\title{
David Carroll Cochran et John C. Waldmeir (éd.), The Catholic Church in Ireland Today
}

\section{Catherine Maignant}

\section{(2) OpenEdition}

\section{Journals}

Édition électronique

URL : http://journals.openedition.org/etudesirlandaises/4680

DOI : 10.4000/etudesirlandaises.4680

ISSN : 2259-8863

Éditeur

Presses universitaires de Rennes

Édition imprimée

Date de publication : 30 juin 2015

Pagination : $371-373$

ISBN : 978-2-7535-4082-8

ISSN : 0183-973X

Référence électronique

Catherine Maignant, « David Carroll Cochran et John C. Waldmeir (éd.), The Catholic Church in Ireland Today ", Études irlandaises [En ligne], 40-1 | 2015, mis en ligne le 30 juin 2015, consulté le 20 avril 2019. URL : http://journals.openedition.org/etudesirlandaises/4680

Ce document a été généré automatiquement le 20 avril 2019.

(c) Presses universitaires de Rennes 


\title{
David Carroll Cochran et John C. Waldmeir (éd.), The Catholic Church in Ireland Today
}

\author{
Catherine Maignant
}

\section{RÉFÉRENCE}

David CARRoll Cochran et John C. WALDMEIR (éd.), The Catholic Church in Ireland Today, Lanham/Boulder/New York/Londres, Lexington Books, 2015, ISBN 978-1-4985-0252-8.

1 The Catholic Church in Ireland Today est un ouvrage collectif qui trouve son origine dans un symposium organisé à Loras College (Dubuque, Iowa, USA). Son ambition, telle qu'exprimée dès la préface, est à la fois de proposer un panorama de l'état du catholicisme en Irlande aujourd'hui et de déceler les marques de résilience, de renouveau, en un mot d'espoir face aux indicateurs alarmants. Le terme d'espoir place d'emblée le lecteur dans une optique catholique, qui est globalement celle des auteurs. Le lecteur français trouvera dans les différents chapitres une approche très intéressante de l'intérieur, à la fois analyse critique et définition de pistes vers l'avenir. Il y retrouvera un certain nombre des grandes lignes du débat interne qui, au sein de l'Église catholique, oppose réformistes et traditionnalistes. Les auteurs appartiennent manifestement à la première catégorie. Ils condamnent les archaïsmes anachroniques et les abus de pouvoir de l'institution et placent leurs espoirs à la fois dans le pape François et dans le peuple des fidèles, chez qui ils identifient un attachement réel à la foi et une volonté de faire renaitre des formes religieuses certes héritées du passé, mais adaptées aux besoins du monde contemporain. Le livre séduit par son approche pluridisciplinaire et l'originalité de certaines des thématiques retenues, peu abordées dans d'autres ouvrages du même type. La comparaison avec la situation du catholicisme américain donne par ailleurs un éclairage auquel les spécialistes d'études irlandaises vivant sur le continent européen sont peu habitués, ce qui contribue à l'intérêt de l'ensemble. 
Plusieurs contributeurs sont des spécialistes renommés des questions traitées, ainsi Eamon Maher et John Littleton, directeurs et auteurs de nombreuses publications de premier plan sur le catholicisme irlandais contemporain, qui ouvrent le recueil par une analyse aussi précise qu'implacable sur les déboires de l'Église au cours des dernières décennies. La première partie se clôt sur une réponse américaine aux deux textes précédents et un débat sur les thèmes abordés à partir d'une optique toute différente. L'exercice, résolument novateur produit un résultat tout à fait intéressant. Dans la deuxième partie se succèdent sept chapitres sur des sujets aussi différents que l'impact du post-sécularisme, le lien entre le burnout des prêtres et l'engagement politique, l'évolution de la compréhension du sens de l'expérience missionnaire, ou le parcours migratoire des prêtres polonais. Notons l'intérêt tout particulier du chapitre signé par John C. Waldmeir qui, à partir de trois textes produits au moment du Congrès eucharistique de Dublin en 2012, démontre l'acharnement de l'institution à s'arcbouter sur des positions anachroniques dans un contexte où davantage d'humilité aurait été souhaitable. Le chapitre de Bernadette Flanagan sur le renouveau contemplatif en Irlande est tout aussi remarquable et attire l'attention sur des initiatives peu connues du grand public, qui esquissent un paysage religieux bien plus complexe que ne le donnent à voir les bilans centrés sur l'idée d'un effondrement du catholicisme en Irlande. Les littéraires et spécialistes des médias, enfin, trouveront leur compte dans cet ouvrage, dont certains chapitres centrent une partie de leur analyse sur un débat radiophonique (Matthew o'Brien) ou des textes littéraires (Maher et Auge, qui évoque entre autres le célèbre cas du Father Jack de Brian Friel). En conclusion, The Catholic Church in Ireland Today mérite une lecture attentive. Le livre offre en effet à l'étudiant spécialiste comme au grand public une ouverture sur un monde catholique émergent en quête d'une voie pour construire l'avenir.

\section{AUTEURS}

\section{CATHERINE MAIGNANT}

Université de Lille 